laugh, from my article on the applications of Murphy's Law in libraries, "Murphy, Parkinson, and Peter: Laws for Libraries, "Library Journal 113 (October 15, 1988): 37-41. Those colleagues who wrote to me after the article was published cer- tainly commented on the humor, and truth, of the article.-Jean E. Compton, Head Librarian, Hancock Library of Biology and Oceanography, University of Southern California.

\title{
Microcomputer software for
}

\section{bibliographic instruction statistics}

\author{
By Candace R. Benefiel \\ Humanities Reference Librarian \\ Texas A \& M University
}

and Joe Jaros

Instructional Services Librarian

Texas A \& M University

\section{How to streamline your procedures for keeping BI records using spreadsheet software.}

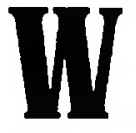

hile bibliographic instruction (BI) is a major project at most academic libraries, statistics gathered concerning BI programs are usually manually compiled, a time-consuming process which often yields only basic totals. More complete statistical outlines of BI activities are essential in providing a clear picture to library and university administrations not only of the quantity of BI activities, but also, over time, of the quality of these activities. Statistical records and analyses may be used to indicate quality in a variety of ways, such as ongoing requests for specific presentations. Even a simple compilation of a BI program's activities, such as a listing of the classes receiving library instruction, will show the number and type of classes and students being reached through varying methods of formal presentation.

Statistics will also enable the librarian to chart more accurately the growth and development of an instructional program and should suggest areas for future concentration of effort. In addition, these records reveal whether the program is geared more toward basic instructional sessions such as tours and classroom lectures, demonstrations of new services, particularly those relating to automated access to library materials, or individual sessions. A detailed knowledge of the program's current content will aid in correcting present problems or imbalances and in determining future needs, directions and emphases. Staffing decisions, always a major area of concern in planning any program, should be aided byverifiable charting of peak times of activity over an extended period.

Although many of the basic patterns of usage are self-evident, especially to the experienced BI librarian, who has observed and coordinated BI activities over several years or more, often these trends are not as apparent to administrators, particularly those outside the library. It need hardly be stated that an administrator, whether at library or 
university level, will certainly be more apt to believe a statistical report than an unsupported generalization, regardless of the years of experience from which the conclusion is drawn. Therefore, many BI librarians are in need of more detailed statistics regarding their programs, preferably without adding to the burden which record-keeping already presents. Furthermore, consolidation of this information into a readily accessible database should simplify the gathering of weekly, monthly, and annual statistics.

\section{Background}

Sterling C. Evans Library is the central library for an expanding student population at Texas A \& $M$ University, which in the fall of 1987 numbered over 39,000. BI has been a long-standing concern at the library, with a program dating back almost fifteen years. In its present form, the BI program offers a variety of instructional activities, centering around the traditional group guided tour, but also including individualized graduate student counseling sessions, classroom demonstrations of automated information retrieval services, specialized lectures, and orientations for new faculty and staff. In addition, as the largest library in the region, Sterling C. Evans Library is also aware of its community responsibility, and works with non-university groups in providing library instruction and services.

The growing undergraduate population of the university has forced a constant re-evaluation and revision of the program in order to include new technology and services, and also to retain quality of instruction offered to large numbers of students. While the program was originally geared toward the needs of the undergraduate students, over the last three years contacts with graduate students have increased dramatically as faculty and students recognized the value of a session tailored to their specific research needs. Class demonstrations for graduate students of new online and CD-ROM databases have also increased.

Since the beginning of the program, BI statistics at the library were manually compiled, a timeconsuming and repetitive task which involved the same information being recorded in as many as three locations, in order to produce weekly, monthly and yearly statistics in addition to the records kept for scheduling purposes. Requests were originally recorded on tour slips, some information from which was then transferred to a scheduling book. At the end of each week, statistics were recorded on a sheet in the scheduling book. Monthly statistics were then compiled and forwarded to the assistant director for public services, with a duplicate being retained in the Reference Division. Each of these records contained similar information, but each had a unique portion, so that the compilation of annual statistics involved consolidating all three sources.

While the statistics generated in this fashion did enable BI librarians to keep an instructional session count and an approximate head count, differentiating between graduate and undergraduate students, and to identify peak times of BI, these basic statistics did not allow for any qualitative analysis of this activity. Under this manual record-keeping system, the BI librarian could not tell without recounting from the tour slips which departments or colleges were requiring instructional sessions, or what percentage of requests each department represented. The system also made it impossible to keep track of special requests by professors or any problems needing future attention without making a separate file which was not easily accessed. In addition, putting materials into graph format was not possible without a great deal of manual counting and drawing.

\section{Methodology}

In order to generate more detailed statistical reports which would aid in examining and maintaining quality $\mathrm{BI}$ services at Texas $\mathrm{A} \& \mathrm{M}$ University, an automated record-keeping program was implemented in early 1987. A new software package, PFS Professional File, was selected to replace the cumbersome manual means of statistics gathering formerly used. Several software packages were examined on the basis of a predetermined set of criteria felt to be essential to the successful progress of the project, the criteria for selection being determined by the BI librarian and the head of the Reference Division. Foremost among the considerations was the flexibility of the package, which needed, in effect, to be a file-management program for a small to medium-sized database. At least as important as flexibility, however, was the simplicity of the software package. The plan called for the package to be used infrequently, and quite possibly by a number of staff members. In addition, the package selected was to be used with a minimum of programming on the part of the users. Therefore, a software package which was difficult to learn, or one that would force the department to rely upon one staff member as a departmental "expert," would not be suitable. The BI librarian felt that a menu-based package would be the best choice for ease of use under these circumstances. Another feature desired was easy interface with graphics and spreadsheet programs, in order to allow for organized and readily understood presentation of the statistical reports generated by the software package. Customized printing options, which would allow for selected portions of the data file to be printed off as needed, were among the 


\section{Graduate vs. Undergraduate Sessions}

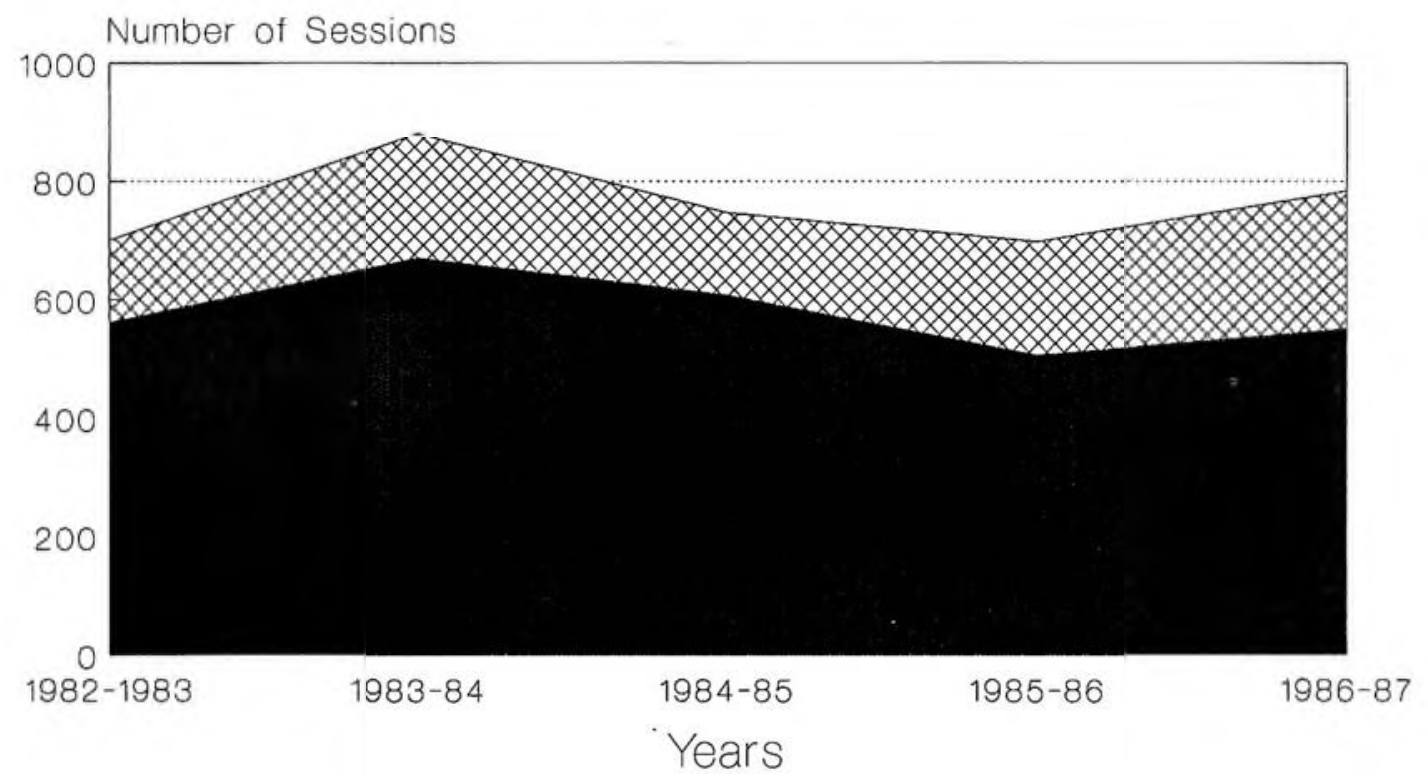

Undergraduate $x \times x$ Graduate

Figure 1. Graduate vs. undergraduate sessions.

considerations. And, as always, the expense of the package was a factor, although not, in this case, an overriding concern.

A number of possible software packages were identified, and reviews of these packages were read and compared with regard to the various criteria. At the time this project was initiated, a literature search found no articles related to the problem of $\mathrm{BI}$ statistics, although a recent article by Wells and Gadikian describes the use of dBase III in a similar

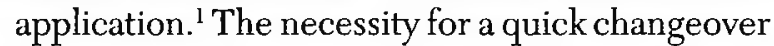
from manual to automated recordkeeping, however, and the desire for the acquisition of a software package which would require only minimal programming precluded the selection of this program for the project at hand. PFS Professional File appeared, at the time the project was begun, to be the best suited for this application, especially in the areas of expense and simplicity. Any package, however, which met the specifications relative to a BI statistics project could have been used for such a purpose.

In addition, a new BI appointment form was developed which allowed for information to be recorded in a more logical fashion to facilitate data

${ }^{'}$ Margaret R. Wells and Randolph S. Gadikian, "BISTATS: Using dBase III to Compile Library Instruction Statistics," Research Strategies 5(Fall 1987): 180-185. entry. The new form, essentially a modification of the previous one, in effect reorganizes the fields to be entered into the data file, placing them in an easy order for entry. Space for added information, allowing for a better picture of the program, was also built into the new form. The added information provided a brief evaluation of degree of activity at any given time, and also allowed a continuing record of postponements, no-shows, cancellations, and problems.

The staff member taking reservations for instructional sessions recorded pertinent information, such as date and time requested, and class size and type, as well as any special needs, before turning the form over to the head of Instructional Services for scheduling and the assignment of the session to the appropriate librarian. After an instructional session had taken place, the data from the appointment form, with any additional notes or revisions added by the librarian, was then entered into the program by non-professional personnel.

Once the program was in place, data entry could be done quickly and effectively by a clerk or student without professional supervision. The file created using this software enabled the BI librarian to produce detailed statistical reports on the BI program. Included in this data were records of times of peak BI activities, and profiles of the distribution of requests for $\mathrm{BI}$ from the various academic departments of the university. Another 


\section{Tours by College}

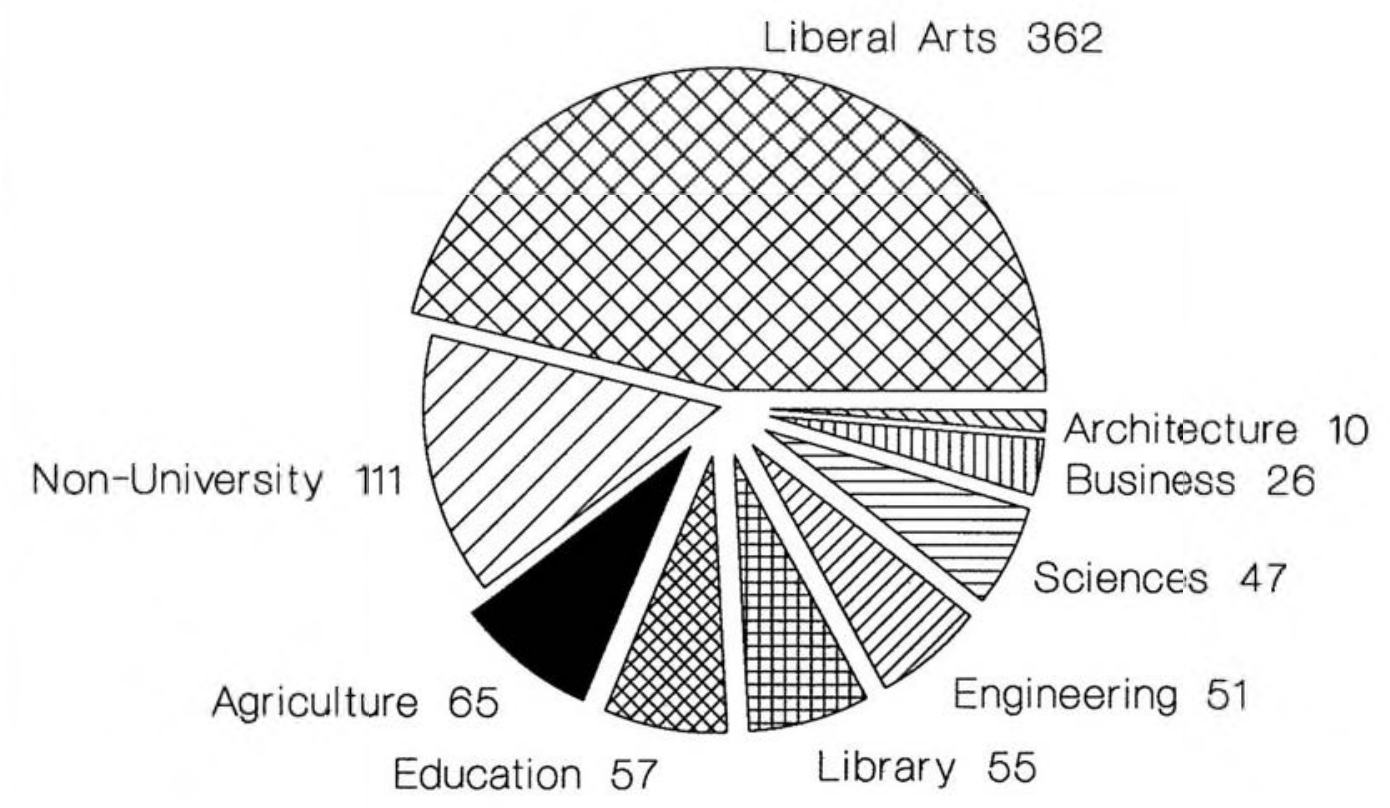

Figure 2. Tours by college.

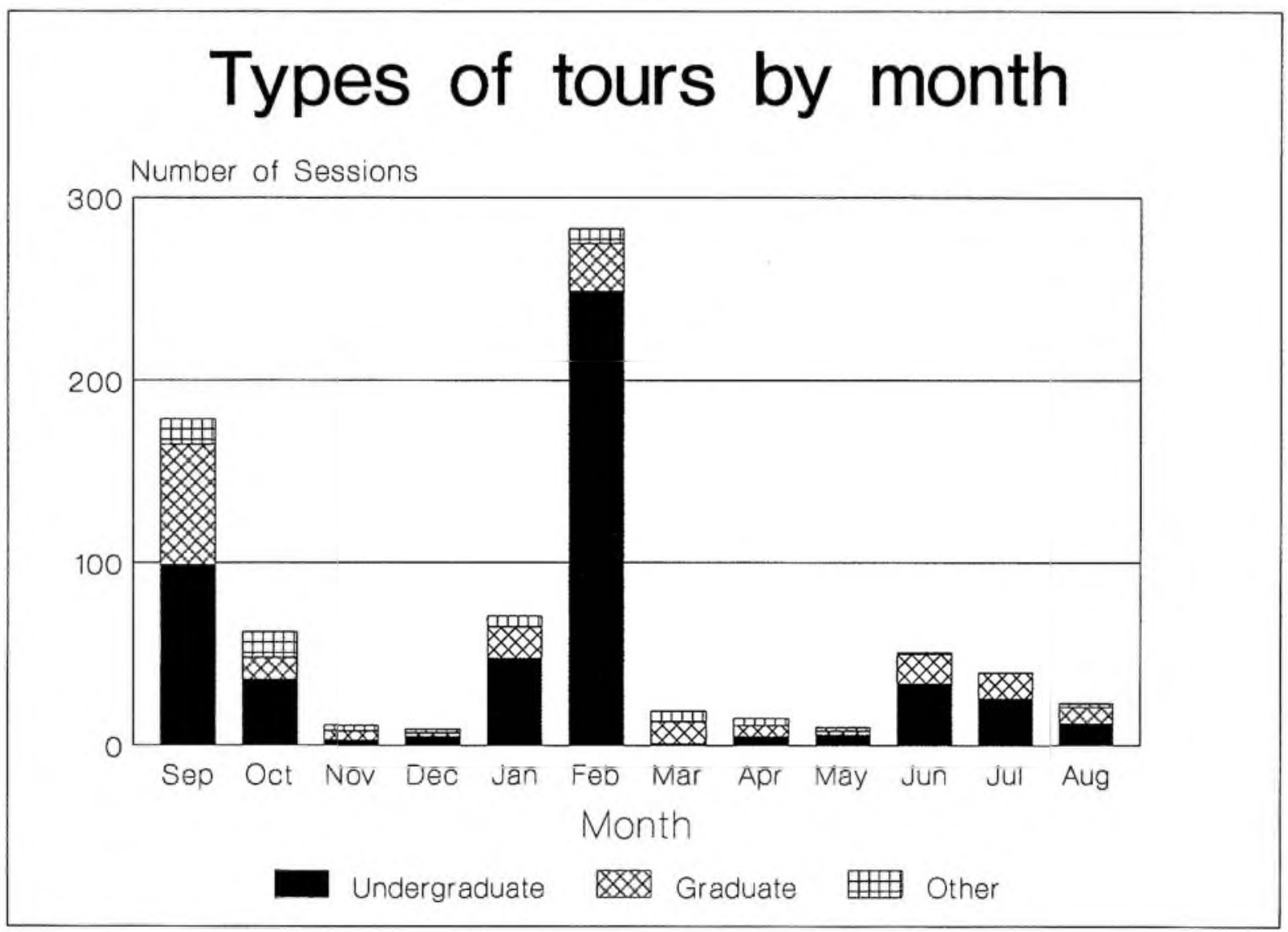

Figure 3. Types of tours by month. 
application was the production of tables detailing the representation of levels of classes receiving instructions (see Figure 1), so that the proportion of graduate to undergraduate students served became readily apparent, revealing the changing emphases of the program. A record of the assignment of instructional activities to specific librarians was easily accessed.

Although the automated record-keeping system was actually implemented at the beginning of the 1987 Spring semester, it was decided that in order to ensure an adequate test of the system's capabilities, the data for the 1986 Fall semester would also be entered into the data file. During the 1986-1987 academic year, 440 group instructional sessions, 233 individual Graduate Student Counseling sessions, and 111 non-university tours or other sessions were given to approximately 15,150 students, providing more than sufficient data for testing purposes. This data was entered in the program, and accordingly used to generate several prototype reports which were then used to analyze the nature of $\mathrm{BI}$ activities during that time period.

\section{Results}

Using the data file produced by inputting information collected from the revised BI appointment form, the investigators were able to generate reports efficiently to illustrate various functions of the BI program. The reports included printouts on types of tours, comparisons of numbers of graduate students and undergraduate students served, the total number of tours per month for evaluation of peak demand periods, and numbers of tours in terms of requesting departments. The resulting statistical materials were used to formulate graphs, by means of PFS Graph software, to illustrate more clearly BI needs and activities (see Figures 2 and 3). The initial success of the automated statistical record-keeping project has gained it a continuing place in the BI program.

\section{Conclusions}

The program as implemented at Sterling C. Evans Library allowed for efficient collection and manipulation of statistical data relating to bibliographic instruction activities. In comparison with the manual methods which have traditionally been used at the Evans Library, PFS Professional File enabled BI librarians to analyze quickly and easily patterns of usage, types of instruction provided, and category of user. In addition, the initial testing of the program also revealed further applications which will be utilized in future. With this software, it will be possible to create tables detailing BI participation by various librarians, allowing for performance evaluation and workload analysis.
Course and class number listings for instructional sessions are now readily available, including names of requesting instructors.

As the library expands its proposed program of instructional outreach throughout the university, the ability to prepare mailing labels for contacting instructors interested in specific BI activities may be used to advantage. In addition, easily produced mailing labels will facilitate mailings for research projects on BI, or evaluations of existing and new programs in this field. Specially tailored statistical reports can be produced on demand. Identification of problems, formerly difficult to impossible, largely depending on the memory of the BI librarian, will be simplified, as the software allows reports to be generated on the problems and special needs of specific classes or instructors. Enhancement and rapid, timely production of annual reports is made possible through use of the data file, which will alleviate a laborious, time-consuming task faced by the BI librarian. The creation and continuous enlargement of a comprehensive database on BI activities will establish, over time, a body of information useful for purposes of comparisons and predictions of future activities.

\section{Add your favorites to Sin List \#2}

The ALA Committee on Professional Ethics seeks "sins" for updating its Ethics Sin List brochure.

The brochure lists such situations as using patron records for political purposes or not providing full service because the request is a homework assignment. Could these situations be unethical? The purpose of the brochure is to stimulate discussion about questions of ethics.

The committee is particularly interested in obtaining situations from academic libraries. Send suggested sins to: Sin List \#2, Committee on Professional Ethics, ALA Office for Intellectual Freedom, 50 E. Huron St., Chicago, IL 60611 .

\section{Popular Culture meeting}

The Popular Culture Association will meet in Toronto on March 7-10, 1990. Scholars who work in all aspects of popular culture will meet and share common interests. Anyone interested in presenting a paper on a topic related to popular culture and libraries should write to Barbara Moran, Associate Professor, School of Information and Library Science, University of North Carolina, Chapel Hill, NC 27514-3360. 


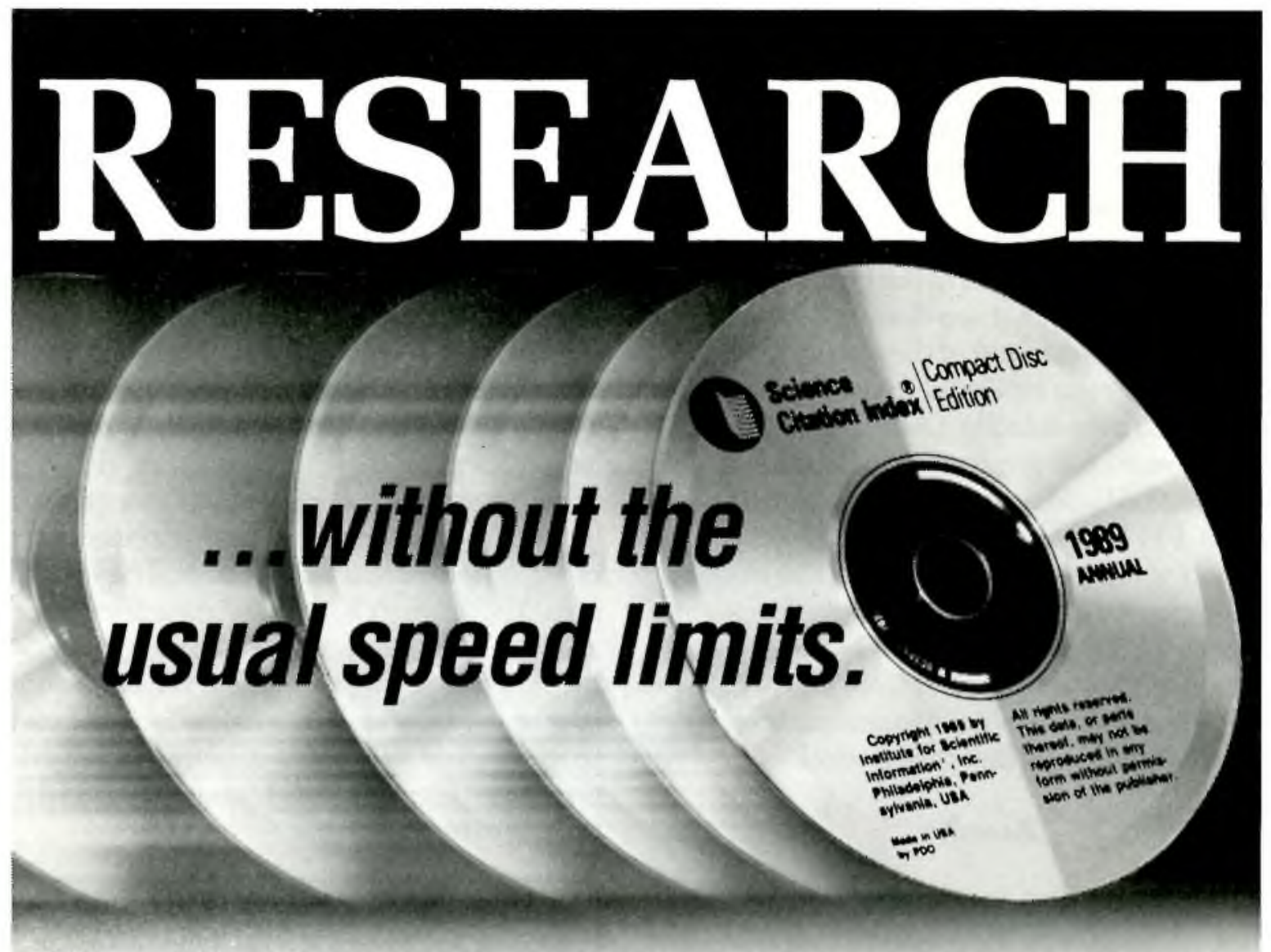

he first time you run the new, enhanced Science Citation Index Compact Disc Edition, you'll know what we mean. It's built for speed.

Speed that translates into instant access to the bibliographic data from 3300 sci-tech journals. The journals you depend on to keep your research going full speed ahead.

But the CD Edition does more than go faster-it goes farther. An exclusive hypertext feature called related records leads you to other records having references in common with the ones you've already retrieved ... expanding your search with a few simple keystrokes.

And even though Laserdisk Professional magazine named the $S C I{ }^{\circledR} \mathrm{CD}$ Edition "Product of the Year," we went back and made it better. Now on a single disc, it's easier than ever to use.

Call us toll-free at: 800- 523-1850, ext. 1405 or write us at the address below to reserve your free trial copy.

Find out what it 'slike/to work without speed limits.

Science Citation Index ${ }^{\circledR}$ Edition
Institute for Scientific Information ${ }^{(1)}$ 3501 Market Street

Philadelphia, PA 19104 U.S.A. 